\title{
Extracutaneous Dissemination of Disease
}

National Cancer Institute

\section{Source}

National Cancer Institute. Extracutaneous Dissemination of Disease. NCI Thesaurus.

Code C39625.

A finding indicating the presence of disease beyond the skin. 